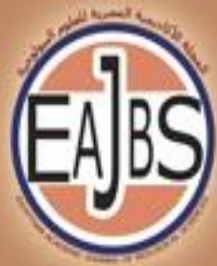

EGYPTIAN ACADEMIC JOURNAL OF
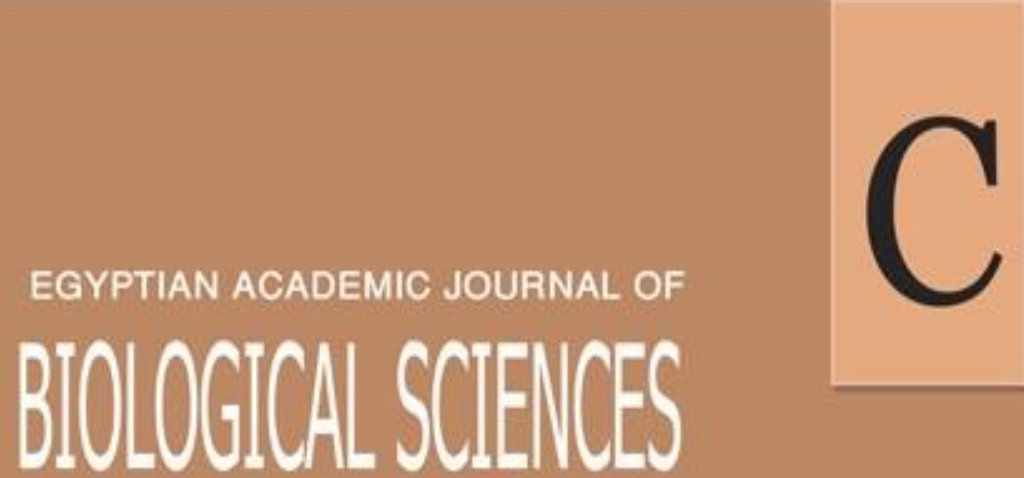

PHYSIOLOGY \& MOLECULARBIOLOGY
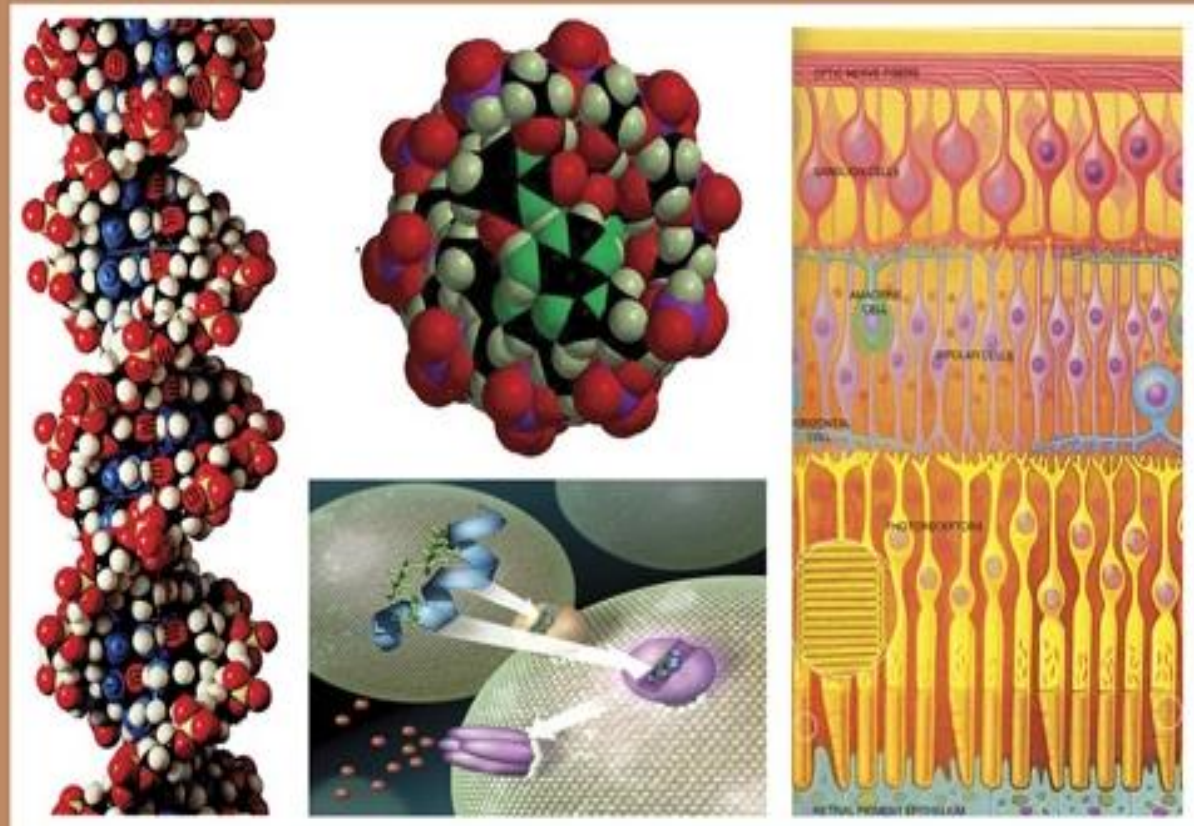

ISSN

2090-0767

WWW.EAJBS.EG.NET

Vol. 14 No. 1 (2022) 

Egypt. Acad. J. Biolog. Sci., 14(1):13-20 (2022)

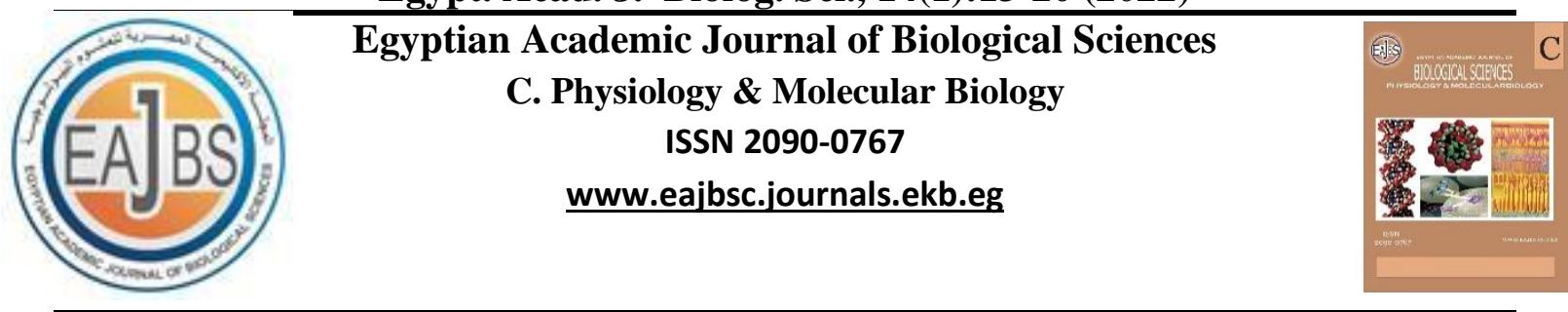

Antifungal Studies of Alkaloids and Flavonoids of Asparagus albus from the Arid Region of Algeria

\author{
Omar, Alami ${ }^{1}$, Mustapha Mahmoud, Dif ${ }^{2 *}$ and Amel, Berrichi ${ }^{1}$
}

1-Institut of science, Nour Bachir Center university, El Bayadh, Algeria, 32000

2-Institut of science Nour Bachir university center, El Bayadh, Algeria, 32000

Ecodeveleopment des espaces laboratory, nature and life faculty, UDL, SBA, 22000

*E. Mail: mustitus17@hotmail.com

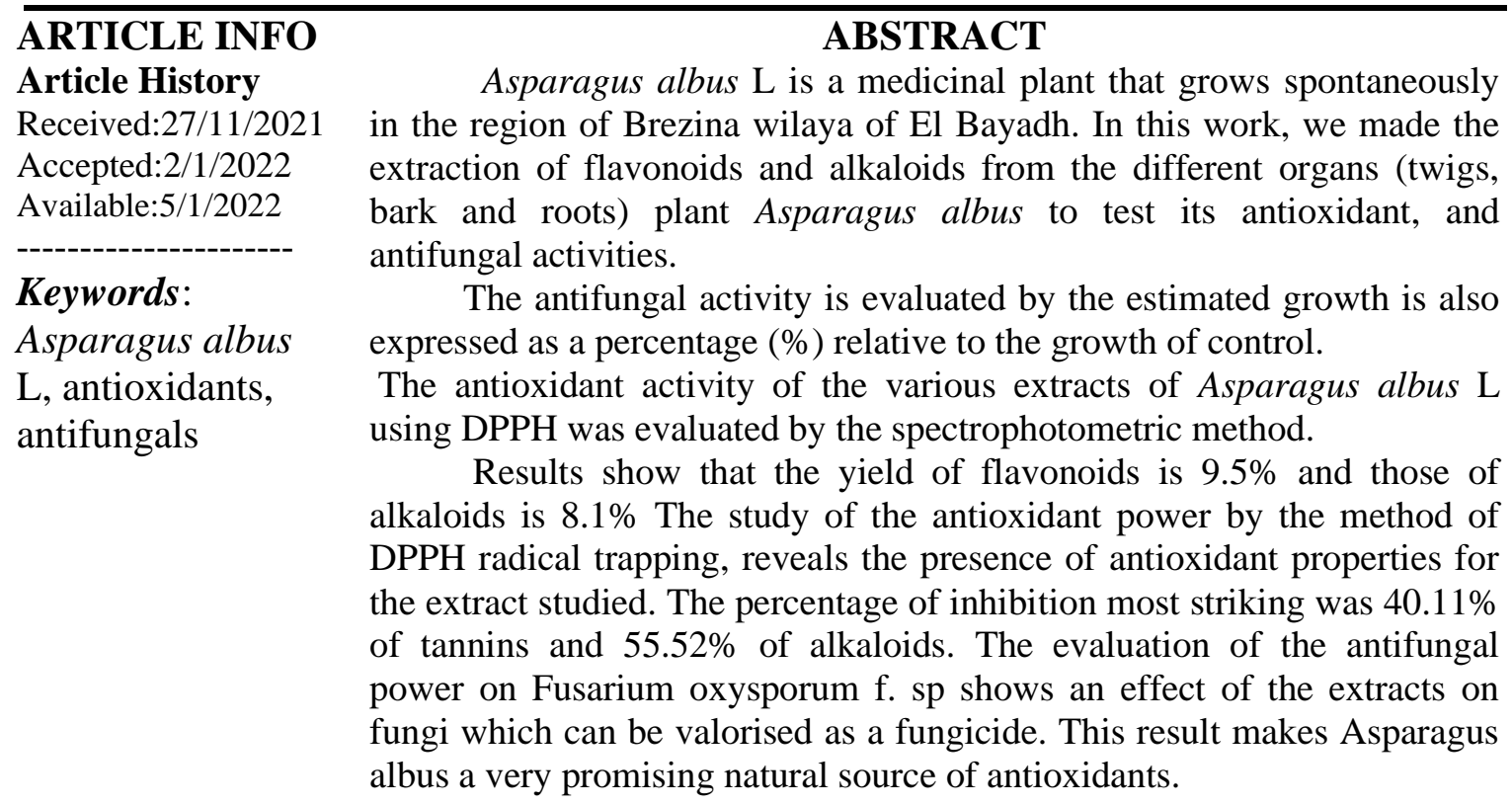

\title{
INTRODUCTION
}

Fungi are one of the most important groups of organisms on earth. They play a key role in a large number of ecosystems. (Schmit et Mueller,2007) The infection of plants by a phytopathogenic fungus takes place according to a process, called the "disease cycle", the complexity of which varies according to the species, but which always includes a certain number of obligatory phases (inoculation, adhesion, germination, penetration, and invasion) (Francisco-Cruz et al., 2014) Phytopathogenic fungi are capable of infecting any tissue at any stage of plant growth, following a complex biological cycle that may include phases of sexual or asexual reproduction (Garrido et al., 2012)

Secondary metabolites designate a metabolite whose taxonomic distribution is restricted and whose contribution to cell function or plant development is insignificant (Gravot et al,, 2008) Secondary metabolites are not vital to the body but necessarily play an important role in the complex enzymatic machinery necessary for their production. They have ecological roles (allomone, pheromones...). 
These molecules were selected during evolution for the interaction they have with a receptor in another organism. They, therefore, represent a great potential source of therapeutic agents (Thomas, 2009). They could play a role in the defense against herbivores, and in the relationships between plants and their environment: several phenolic compounds participate in the UV filtration, floral pigments are essential for pollination processes such as alkaloids, tannins, flavonoids (Gravot et al., 2008).

Asparagus albus $\mathrm{L}$ is a species of plant belonging to the genus Asparagus, to the family of Asparagaceae. It is Mediterranean wild asparagus. (Asparagus Production in Canada. April 1983). Our study consists in researching the biological activity of extracts of the plant Asparagus albus L growing spontaneously in the region of Brezina, Wilaya of El Bayadh.
MATERIALS AND METHODS Preparation of Plant Material:

Sampling: The harvest of the different organs (twigs, bark and roots) of the species was carried out during the month of March 2018, in the region of Brezina, $84 \mathrm{~km}$ from the wilaya. of El Bayadh with random sampling. In El Bayadh Ghassoul -Brezina axis $\left(33^{\circ} 41 ' 10\right.$ "N, $1^{\circ}$ 0' 50" E) (Fig.1).

The Wilaya of El Bayadh has three main areas: The High Plains, the Saharan Atlas and the Pre-Saharan area. The predominant bioclimate in the study area is arid (100-400 mm / year), With a plant formation of E'Remth (Arthrophytum scoparium) from a geomorphological point of view, the following components are distinguished:

Plant material was identified based on the identification key (Quezel et al., 1963) and confirmed by Dr. Dif Mustapha Mahmoud.

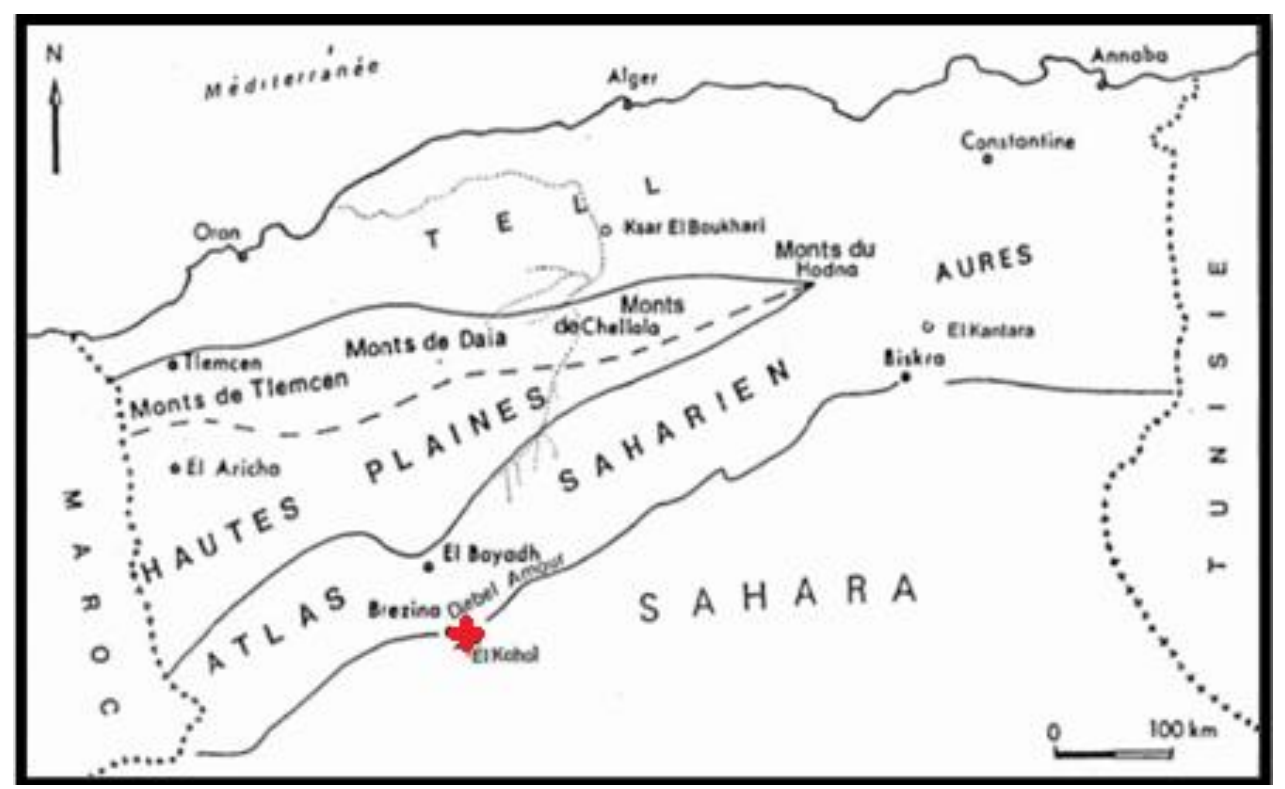

Fig. 1: Situation map of the Brezina in the study area (Bensalah, 1991)

\section{Drying and Conservation:}

After harvesting, the plant was cleaned then dried in the open air for 10 days. The vegetable powder was stored in hermetically sealed glass vials; which will be used later for the preparation of the various extracts (Kanoun et al.,2014).

\section{Extraction of Total Alkaloids:}

The extraction of total alkaloids was done according to the protocol of Makkar et (Makkar et al.,2007) with an aliquot of the plant material is extracted with $400 \mathrm{ml}$ of $10 \%$ acetic acid in methanol. The extract was macerated for 
72 hours with stirring and kept away from light. After filtration, the extract is concentrated with a rotary steamer to $1 / 4$ of its initial volume, and then precipitated by the addition of concentrated ammonium hydroxide). The two phases obtained are extracted with chloroform until their total exhaustion, and the organic phase is evaporated to dryness at $40{ }^{\circ} \mathrm{C}$. The residue obtained from the total alkaloids is stored in the refrigerator at $+4^{\circ} \mathrm{C}$ (Clarke, 1970)

\section{Fractionation of Polyphenols:}

To proceed with the various experiments (dosage of phenolic compounds, antioxidant activity, antifungal activity), solid-liquid extraction was realized to preserve the compounds of the ground plant as specified (Sanogo et al.,2006).

The choice, to macerate the vegetable powder, fell on two solvents of different polarities: Acetone (70\%). For this, our extracts have been prepared as a follow-up.

After stirring and 24 hours of maceration at room temperature, the solution was protected from light, the extracts were filtered through filter paper. The extracts are then concentrated and dried using a Rota steamer set at $45^{\circ} \mathrm{C}$ until the dry residue is obtained (Yrjönen et al.,2004).

\section{Extraction of Lipophilic Flavonoids:}

The methodology adopted for the liquid-liquid fractioning is divided into two stages: The first stage: the addition of $60 \mathrm{ml}$ of chloroform to the acetone extract in an embolus without stirring, then it was recovered (Sanogo et al.,2006).

\section{The Yield:}

The organic phases obtained are then concentrated to dryness under reduced pressure and then weighed to determine the extraction yield (R\%) according to the formula opposite:

$\mathrm{R} \%=$ (mass of dry residue $/$ mass of vegetable powder $) \times 100$.

\section{Antifungal Test:}

Preparation of the Dilutions of The Extracts:

The dried extracts or concentrates were dissolved in Phosphate Buffer, knowing that the solvent should not prevent the biological process (Yrjönen et al.,2004).

like Tom phosphate bridge, which is the most suitable solvent for this type of test because it has no antifungal effect (Mohammedi., 2006) The range of different diluted concentrations of the plant extract was prepared on the culture medium $1 \mathrm{ml}$ of the extract for $19 \mathrm{ml}$. (Satish., 2010).

The PDA and the extract were poured into $90 \mathrm{~mm}$ Petri dishes $(20 \mathrm{ml} /$ dish). [11]. After solidification of PDA, the Petri dishes are seeded with strains of Fusarium oxysporium. The Fusarium oxysporium strains are incubated for 7 days at a temperature of 24-28 ${ }^{\circ} \mathrm{C}$ (Mohammedi., 2006) This technique consists of measuring the growth of colonies over seven days, using the following formula $\mathrm{L}=\mathrm{D}-\mathrm{d} / 2$ : ( $\mathrm{L}$ : mycelian growth, D: diameter of the colony, d: diameter of the implant

The results obtained from the estimated growth are also expressed as a percentage $(\%)$ relative to the growth of control.

I' $(\%)=100 \times(\mathrm{dC}-\mathrm{dE}) / \mathrm{dC}$ ("I" $(\%)$ : Inhibition rate expressed as a percentage, $\mathrm{dC}$ : Diameter of colonies in "positive control" dishes, dE: Diameter of colonies in dishes containing plant extract.

\section{Antioxidant Activity Test of Asparagus} Extracts by DPPH:

DPPH

(2,2-Diphenyl-1picrylhydrazyl) is a stable free radical which absorbs between 512 and $517 \mathrm{~nm}$. In the presence of anti-radical compounds, the purple-coloured DPPH is reduced to the yellow-coloured 2,2 Diphenyl-1picrylhydrazine (Maataoui et al.,2012)

The antioxidant capacity of 
Methanolic extract of Asparagus albus L alkaloids and tannins was evaluated by performing the following: $2.7 \mathrm{ml}$ of a methanolic solution of DPPH $(60 \mu \mathrm{M}$ is mixed with $0.3 \mathrm{ml}$ of the sample of the extract. The absorbance reading is taken at $517 \mathrm{~nm}$ using a spectrophotometer.

The reduction rate of the extracts of asparagus DPPH or the percentage inhibition is expressed by the following formula:

$\mathrm{I} \%=[($ Abs c - Abs e $) /$ Abs c $] \times 100($ Abs c: Absorbance of control. Abs e: Absorbance of the tested sample.

\section{RESULTS AND DISCUSSION}

\section{Solvent Extraction Yield:}

The obtained results of yields extraction of natural compounds highlight that the yield of the flavonoids is $9.5 \%$ and the yield of alkaloids $8.1 \%$ of Asparagus albus L, compared with a plant. The results show that the dry extract contents vary depending on certain parameters of the extraction of bioactive substances, which are: Temperature, extraction solvent, particle size and solvent diffusion coefficient (Bougandoura , 2009)

The Antioxidant Activity of Asparagus albus L Extracts:

The antioxidant activity of the various extracts of Asparagus albus L using DPPH was evaluated by the spectrophotometric method by following the reduction of this radical which is accompanied by its passage from the violet color to the yellow color, measurable at $517 \mathrm{~nm}$.

This effect of the DPPH radical is expressed by the $50 \%$ inhibitory concentration (IC50) which inhibits or reduces $50 \%$ of the initial concentration of DPPH. A low IC50 indicates the highest anti-free radical activity ( Dif et al., 2009, 2015, 2015, 2018).

Inhibition calculations conducted after performing the test on our extracts are summarized in the following (Fig. 2).

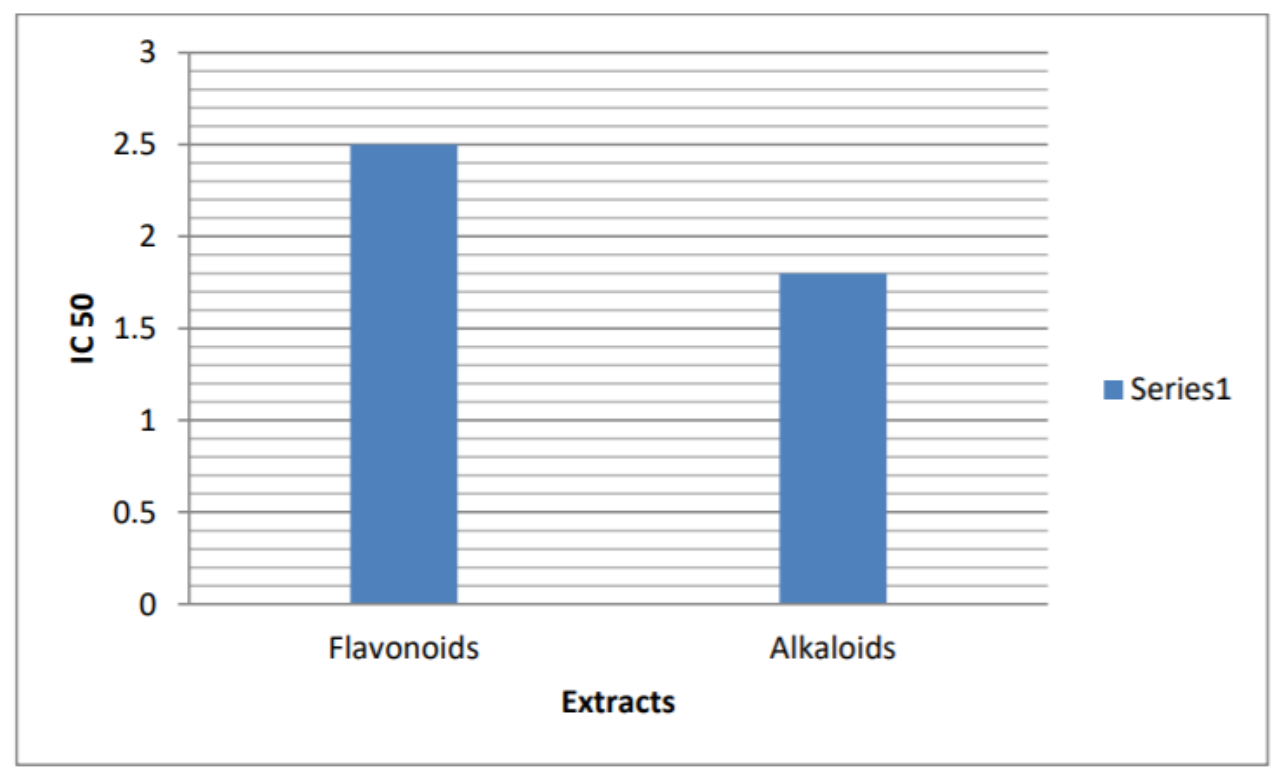

Fig. 2: Evaluation of the antioxidant activity of Asparagus albus L By DPPH scavenging Method (IC50).

The results of the Table indicate that the methanolic extracts of the plant studied gave IC50 inhibition of (2.5 $\mathrm{mg} / \mathrm{ml})$ of the flavonoids and $(1.80 \mathrm{mg} / \mathrm{ml})$ of the alkaloids. Compared to the antioxidant activity of seven species of asparagus from India and to preserved
Asparagus of Spain, it is an average antioxidant activity (Manish et al., 2019)

For the radical scavenging mechanism, the reaction between the antioxidant and DPPH depends on the structural conformation of the antioxidant. Some compounds react rapidly with 
$\mathrm{DPPH}$, reducing the number of DPPH molecules equal to the number of hydroxyl groups (Bond et al., 1997).

The antioxidant effect of the different extracts could be due to their richness in phenolic compounds such as flavonoids and alkaloids.

In fact, polyphenolic substances according to many authors are compounds with high antioxidant potential

\section{Antifungal Activity:}

Our results noticed that the extract of the flavonoids (Figs. $3 \& 4$ ) records a high degree of inhibition on Fusarium oxysporium of the order of $85 \%$ and $71.25 \%$ at the dilution of $1 \mathrm{ml}$ and a medium degree of inhibition of $52.5 \%$ and $41.25 \%$ at the dilution of $0.75 \mathrm{ml}$ and $0.5 \mathrm{ml}$ and a low degree of inhibition at $(37.5 \%$, $35 \%, 31.25 \%$ ) were observed in the dilutions $(0.25 \mathrm{ml}, 0.125 \mathrm{ml}, 0.06 \mathrm{ml})$.

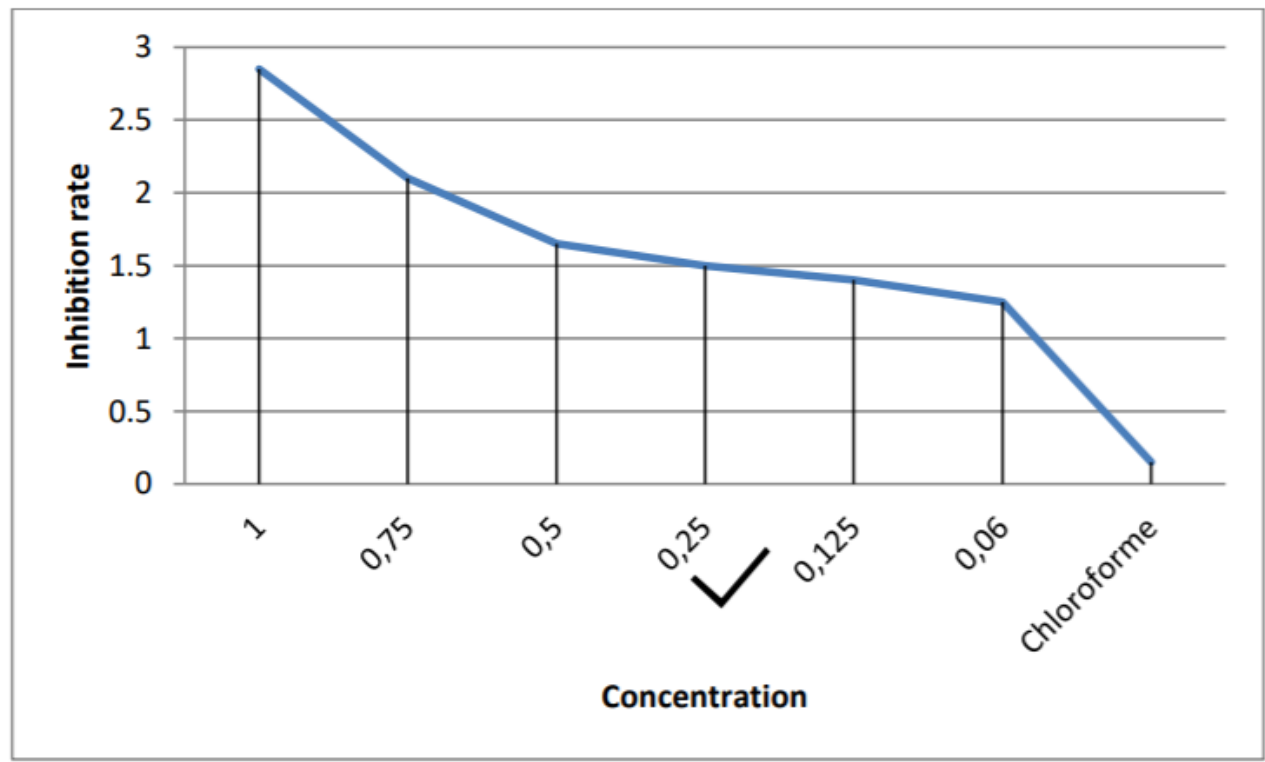

Fig. 3: Evaluation of the rate of inhibition of Fusarium oxysporium treated by extracts of Flavonoids

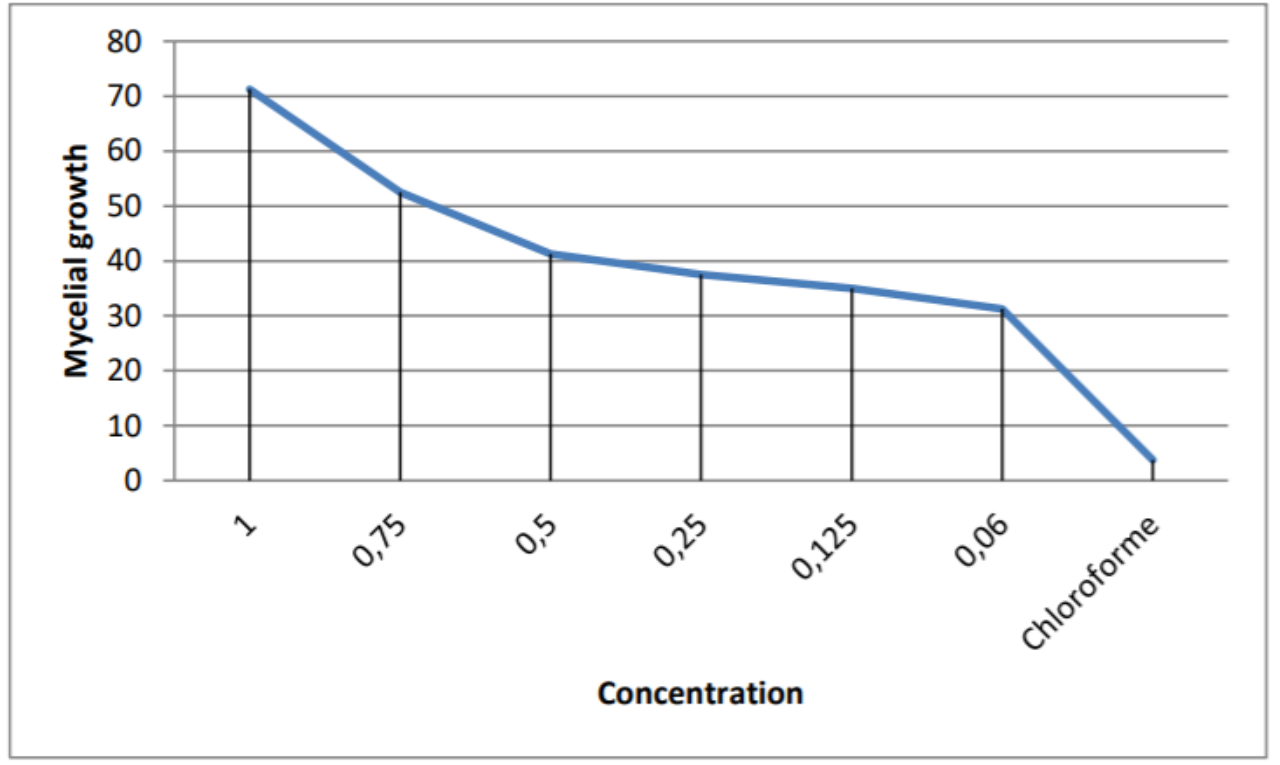

Fig. 4: Estimation of the growth of Fusarium oxysporium. processed by extracts of Flavonoids. 
Our study also noticed that the extract of the alkaloids records (Figs. 5 \&6) a strong rate of inhibition of the order of $85 \%$ and $80 \%$ at the dilution of $1 \mathrm{ml}$ and $0.75 \mathrm{ml}$ and an average rate of inhibition $67.5 \% 0$ at the dilution of $0.5 \mathrm{ml}$ and low yields at $(18.75 \%, 17.5 \%, 12.5 \%)$ were observed in the dilutions $(0.25 \mathrm{ml}$, $0.125 \mathrm{ml}, 0.06 \mathrm{ml}$ ).

In fact, there is no work in antifungal activity, but Jaramillo-Carmona et al.,2019, Have worked in antibacterial activity in the context of antimicrobial effect and have shown that the minimum inhibitory concentration (MIC) of the leaf was at a concentration of $0.125 \mathrm{mg} / \mathrm{mL}$ against $S$. saprophyticus and E. cloacae, also at a concentration of $1 \mathrm{mg} / \mathrm{mL}$ against $S$. aureus and B. subtilis. There was no MIC of the stem extract at any concentration.

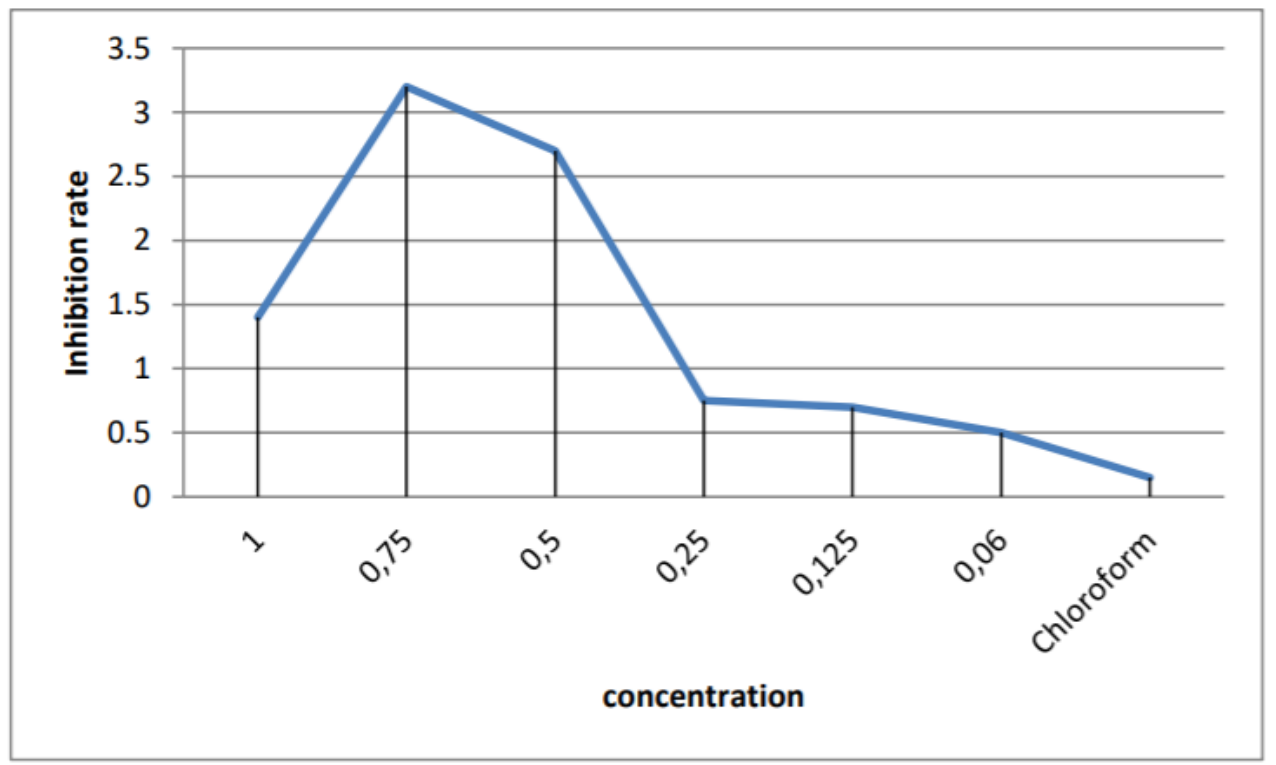

Fig.5: Estimation of the growth of Fusarium oxysporium. processed by extracts of alkaloids.

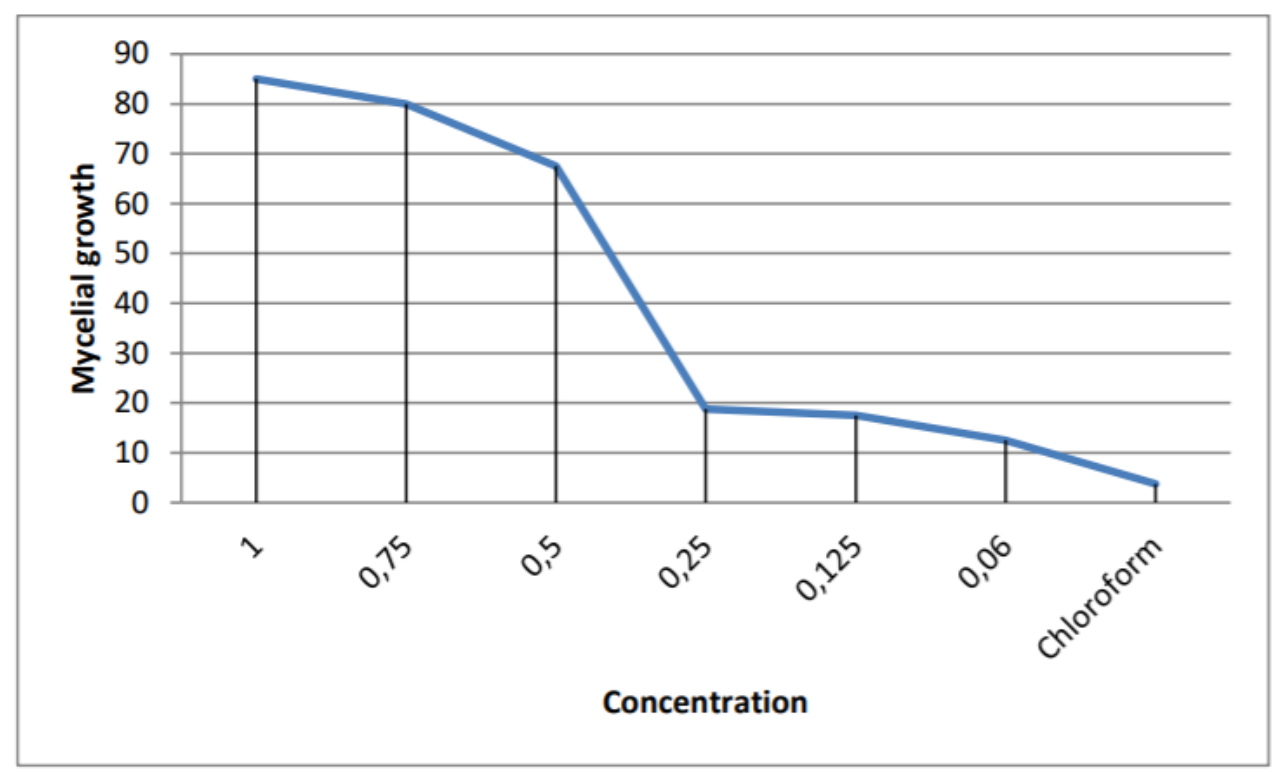

Fig. 6: Evaluation of the rate of inhibition of Fusarium oxysporium treated by alkaloid extracts. 


\section{Conclusion}

The extraction and evaluation of the antioxidant and antifungal activity of Asparagus albus $\mathrm{L}$ from the region of Brezina (El Bayadh Province, Algeria) revealed some important results.

The extraction yields are $9.5 \%$ and $8.1 \%$ for flavonoids and alkaloids respectively

For the antioxidant activity in our work, the antioxidant power of all plant extracts through the DPPH free radical scavenging capacity, in order to locate the extract that represents the highest activity. Our results noticed a significant antioxidant activity IC50 $(2.5 \mathrm{mg} / \mathrm{ml})$ of the flavonoids and $(1.80 \mathrm{mg} / \mathrm{ml})$ of the alkaloids.

The results of this present study show that extracts are able to inhibit fungal growth with a higher and very significant inhibition rate of the order of $85 \%$ and $71.25 \%$ for the extract of the flavonoids and $85 \%$ and $80 \%$ for the extract from alkaloids.

In the end, our study has carried out biochemical and microbial biotechnological techniques reveals the richness of the natural resources of the phylogenetic diversity of the region of Brezina, can be a database for a contribution of the valorization of the natural resources of the area study in the context of sustainable development

\section{REFERENCES}

Bondet. V., Brand-Williams. W., Berset. C., (1997) Kinetics and mechanisms of antioxidant activity using the DPPH free radical method. Lebensmitt Wissenschaft Technologie Food Sci Technol 30:609-61

Bougandoura, N(2009) Pouvoir antioxydant et antimicrobien des extraits d'espèces végétales Saturejacalaminthasspnepta (nabta) et Ajugaiva L. (chendgoura) de l'ouest d'Algérie University of Algeria.

Clarke E. G. (1970) Isolation and Identification of Drugs in Pharmaceuticals. Body Fluids, and Post-mortem Material. Journal of Medicinal Chemistry, 13(2), 338338

Dif M. M., Benchiha H., Mehdadi Z., Benali-Toumi F., Benyahia M., \& Bouterfas K.. (2015)Étude quantitative des polyphénols dans les différents organes de l'espèce Papaver rhoeas

L. Phytothérapie, 13(5), 314-319.

Dif M. M., Toumi F. B., Benyahia, M., \& Bouazza, S. (2015) Influence of solvent concentration on the extraction of phenolic compound and antioxidant activity of 2 lavenders from Benisaf region. Advances in Natural and Applied Sciences, 3, 7-10.

Dif M. M., Toumi F. B., Boukaaza H., Mokaddem F., Benyahi, M., \& Bouazza, S. (2018) Phenolic content and antioxidant activity of Artemisa herba-alba, A medicinal plant from Algerian arid zone. Phytothérapie, 16(2), 91-95.

Francisco-Cruz A., Aguilar-Santelises M., Ramos-Espinosa O. (2014) Granulocyte-macrophage colonystimulating factor: not just another haematopoietic growth factor. Med Oncol31, 774.

Garrido C., Acero F. G. F., Carbú, M., Rodriguez, V. E. G., Liniero, E., Cantoral, J. M. Molecular microbiology applied to the study of phytopathogenic fungi. (2012). Biochemistry, Genetics and Molecular Biology. Rijeka, InTech, 139-156

Gravot A, Jubault M., Hamon C., Lariagon C., Delourme R., Bouchereau A., 
\& Manzanares-Dauleux, M. J. (2008) Differential regulation of root arginine catabolism and polyamine metabolism in clubrootsusceptible and partially resistant Arabidopsis genotypes. Plant Physiology, . 146(4)

Kanoun, K., Belyagoubi-Benhammou, N., Ghembaza, N., \& Bekkara, F. A. (2014). Comparative studies on antioxidant activities of extracts from the leaf, stem and berry of Myrtus communis L. International Food Research Journal, 21(5), 1957

Maataoui B.S, Hmyene A\& Hilali S. (2006) Activités anti-radicalaires d'extraits de jus de fruits du figuier de barbarie (Opuntia ficus indica). Lebanese Science Journal, 7(1): 38

Makkar H. P., Siddhuraju P., \& Becker K. (2007). Plant secondary metabolites. Humana press

Manish K., Pooja M., Raghbir Chand G (2019) antioxidant potential., total phenolic and flavonoid content of roots of seven Asparagus species from north-west India), International Journal of Pharmaceutical Sciences and Research (IJPSR), 10 (8)

Mohammedi Z., (2006.) Etude du pouvoir antimicrobien et antioxydant des huiles essentielles et flavoîdes de quelques plantes de la région de Tlemcen., faculty of sciences Tlemcen university.

Sanogo R., Diallo D,Diarra S., Ekoumou C., Bougoudogo (2006) Activité antibactérienne et antalgique de deux recettes traditionnelles utilisées dans le traitement des infections urinaires et la cystite au Mali. Mali Médical, XXI, (1), 18 24

Sara María J-C., Francisco Javier T-M, Ana Jiménez-Araujo, R GuillénBejarano., and Rocío RodríguezArcos., (2019): "Comparative Analysis of Chemical Compounds Related to Quality of Canned Asparagus." Journal of Food and Nutrition Research, 7(2), 171-182

Satish S., Raghavendra M. P., Raveesha K. A. (2010) Management of seed borne fungal pathogens of sorghum seeds by aqueous extract of Lawsonia inermis L. Journal of Biopesticides, 3(1) 237 -241

Schmit, J. P., Mueller G. M. (2007): An estimate of the lower limit of global diversity. Biodiversity and conservation, 16(1), 99-111.

Yrjönen, Teijo. (2004). "Extraction and Planar Chromatographic Separation Techniques in the Analysis of Natural Products." University of Helsinki, 64 pages 